\title{
Research of Load Leveling Strategy for Electric Arc Furnace in Iron and Steel Enterprises
}

\author{
Yuanchao Wang ${ }^{1, a^{*}}$, Zongxi Xie ${ }^{2, b}$ and Zhihan Yang ${ }^{1, c}$ \\ ${ }^{1}$ School of Electrical and Electronic Engineering, Huazhong University of Science and Technology, \\ Wuhan, 430074, China \\ ${ }^{2}$ Xianning Electric Power Supply Company, State Grid Corporation of China, \\ Xianning, 437100, China \\ aycwang@hust.edu.cn, ${ }^{b} x z x 10 @ q q . c o m$, cyangzhihan@hust.edu.cn
}

Keywords: Electric arc furnace, Impact load, Load leveling, Time-sharing operation, GA-PSO.

\begin{abstract}
The electric arc furnace is an important smelting equipment in modern iron and steel enterprises. However, the load of electric arc furnace is a typical impactive and nonlinear load, and it has a huge effect on power system, electrical equipment and enterprise production. Based on the theory of peak load shifting in power system, a new load leveling strategy called time-sharing operation is proposed, which can be used to stabilize the loads of electric arc furnaces. The active power curve of single electric arc furnace is given, and the load leveling model of multiple electric arc furnaces is built, then a new GA-PSO hybrid algorithm is adopted to solve the model. Two examples of five same and different electric arc furnaces are optimized respectively, and their load fluctuations of synchronous operation and time-sharing operation are analyzed contrastively. The results indicate that the time-sharing operation strategy is effective in load leveling.
\end{abstract}

\section{Introduction}

The electric arc furnace has been widely used in metallurgical industry with its advantages of reliability, flexibility, fast smelting speed and superior smelting quality. And it is gradually developing into the most important smelting equipment in modern iron and steel enterprises [1]. However, the load of electric arc furnace is a typical impactive and nonlinear load, which will have a huge influence on the stability of power system, the safety of electrical equipment, the quality of enterprise product and so on $[2,3]$. Therefore, it is necessary to research the load leveling strategy for electric arc furnace in iron and steel enterprises.

At present, the main measures of load leveling are cutting peak, filling valley and peak load shifting. Specifically, the methods of cutting peak mainly have direct load control and interruptible load control, the methods of filling valley mainly have increasing the electrical equipment and energy storage, and the methods of peak load shifting mainly have adjusting the working time and holiday order [4]. The implementation strategy of interruptible price and its theory of peak load shifting were analyzed in [5]. Reference [6] researched the regulation technology of air-conditioning load in commercial buildings for balance of power grid peak and valley. Reference [7] discussed the use of energy storage battery in alleviating peak-valley difference. References [8] and [9] optimized the peak-valley difference in power grid load curve by ordered charging of electric vehicles. And also we can dispatch the shiftable loads to alleviate peak-valley difference [10]. However, the above methods are mainly focused on the normal load control of power system, and there are few studies on the impact load leveling of electric arc furnace.

This paper presents a new optimization strategy called time-sharing operation for load leveling based on the theory of peak load shifting. Then we use the strategy to stabilize the load of electric arc furnace, in order to adjust the load curve and optimize the load characteristic. Firstly, the working principle and load characteristic are introduced, and the active power curve of single electric arc furnace is given. Secondly, the load leveling model of multiple electric arc furnaces is built, and a new 
GA-PSO algorithm is adopted to solve the model. Finally, the validity of the proposed strategy is verified by two optimization examples.

\section{Working Principle and Load Characteristic}

Basic Working Principle of Electric Arc Furnace. The electric arc furnace is steel-making equipment that takes electric energy as the heat source. And the electric energy is converted into heat energy by the arc discharging between the electrode and the burden, when the arc and its radiation will melt the metals along with slags. By a series of physical and chemical reaction, it can smelt various components of steel and alloy [11]. According to the working principle, it can be divided into direct heating arc furnace, indirect heating arc furnace and resistance arc furnace, and the modern electric arc furnaces mostly are direct heating arc furnace. The mechanical parts of electric arc furnace mainly include metal component, electrode clamper, electrode lifting device, furnace body tilting device, furnace cover rotating device and so on [12]. Fig. 1 shows the basic structure of an electric arc furnace.

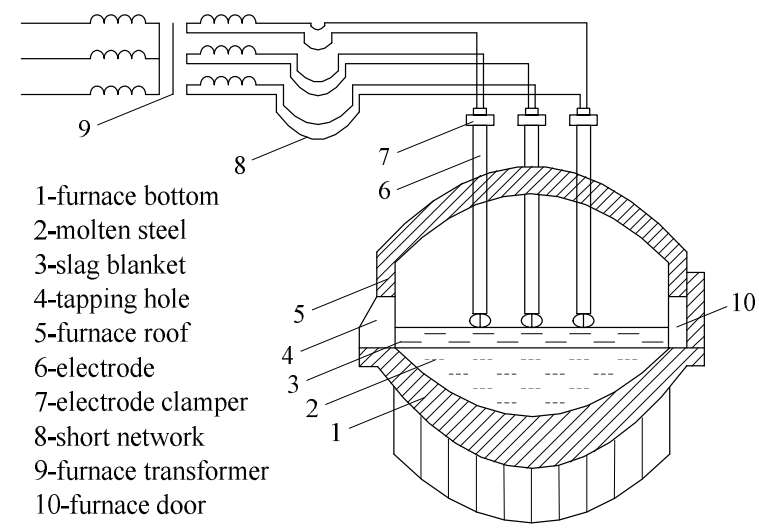

Fig. 1 Schematic diagram of electric arc furnace.

Typical Load Characteristic of Electric Arc Furnace. The steel-making processes of electric arc furnace mainly include three stages of melting period, oxidizing period and reducing period. And the different stages have the different requirements of temperature and input power. During the melting period, the frequent electrode short circuit is easy to cause the current change sharply. During the oxidizing period, the boiling of molten steel is easy to cause the arc length fluctuate randomly [13]. For all these reasons, the load of electric arc furnace is random, impactive and nonlinear. The electric arc furnace always operates with some characteristics of low voltage, high current and dynamic changes. And there are some power quality problems, such as low power factor, large harmonic content and unbalanced three-phase load. It may also cause power system voltage fluctuation and flicker. Some power supply curves of electric arc furnace were presented from different angles in [12] $[13,14]$. Combining with the steel-making process, we can build the load model of electric arc furnace. Fig. 2 shows a typical active power curve of electric arc furnace.

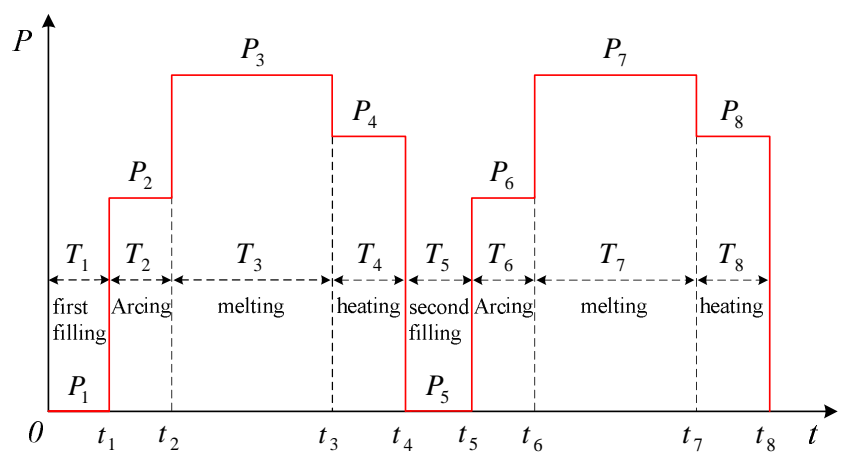

Fig. 2 Typical active power curve of electric arc furnace. 
According to the active power curve, an active power function of the electric arc furnace load can be derived as follows:

$$
P(t)=\left\{\begin{array}{lr}
P_{1}, \quad k T<t \leq t_{1}+k T \\
P_{2}, t_{1}+k T<t \leq t_{2}+k T \\
P_{3}, t_{2}+k T<t \leq t_{3}+k T \\
P_{4}, t_{3}+k T<t \leq t_{4}+k T \\
P_{5}, t_{4}+k T<t \leq t_{5}+k T \\
P_{6}, t_{5}+k T<t \leq t_{6}+k T \\
P_{7}, t_{6}+k T<t \leq t_{7}+k T \\
P_{8}, t_{7}+k T<t \leq t_{8}+k T
\end{array}\right.
$$

where, $T$ is the steel-making cycle, $T=T_{1}+T_{2}+\cdots T_{8}, k=0,1,2, \cdots$.

\section{Load Leveling Strategy of Electric Arc Furnace}

Optimization Model of Time-sharing Operation. After building the load model of electric arc furnace, we propose the load leveling strategy of time-sharing operation, which is based on the theory of peak load shifting in power system. The time-sharing operation strategy is about how to regulate and control the each load time-sharing start and interleaving run, and then make the synthetic load of multiple electric arc furnaces become smoother and flatter. More particularly, we can optimize the start time of every electric arc furnace, and control them running in different period, then stabilize the synthetic load curve by peak load shifting. Here we select the minimum variance of synthetic load curve as the objective function to describe the load fluctuation, and then the load leveling optimization model applied to the active power load of electric arc furnace is built. The optimization model is shown as follows:

$$
\min F=\frac{\sum[P(t)-\bar{P}(t)]^{2}}{N}
$$

$$
\left\{\begin{array}{r}
P_{i}(t)=\left\{\begin{array}{l}
P_{1}, \quad k T<t \leq t_{1}+k T \\
P_{2}, t_{1}+k T<t \leq t_{2}+k T \\
P_{3}, t_{2}+k T<t \leq t_{3}+k T \\
P_{4}, t_{3}+k T<t \leq t_{4}+k T \\
P_{5}, t_{4}+k T<t \leq t_{5}+k T \\
P_{6}, t_{5}+k T<t \leq t_{6}+k T \\
P_{7}, t_{6}+k T<t \leq t_{7}+k T \\
P_{8}, t_{7}+k T<t \leq t_{8}+k T
\end{array}\right. \\
P(t)=P_{1}\left(t-t_{1}\right)+\cdots P_{i}\left(t-t_{i}\right)+\cdots+P_{n}\left(t-t_{n}\right) \\
0 \leq t_{1} \leq T, \cdots 0 \leq t_{i} \leq T, \cdots, 0 \leq t_{n} \leq T
\end{array}\right.
$$

where, (2) is the objective function, (3) is the constraint condition. $\bar{P}(t)$ is the average value of synthetic active power. $T$ is the operation cycle of electric arc furnace. $n$ is the total number of all electric arc furnaces. And $k=0,1,2, \cdots, n=1,2,3, \cdots, i=1,2, \cdots, n$. The final target is to solve the optimal value of each electric arc furnace, $T_{\text {best }}=\left[t_{1}, t_{2}, \cdots, t_{n}\right]$.

Model Solving Based on GA-PSO Algorithm. Particle swarm optimization (PSO) is a stochastic optimization algorithm based on swarm intelligence principles. There is a good ability to find the optimal values by iterative calculation, especially for some complex engineering problems. But it is easy to cause the fast convergence effect of particle swarms, when the particles gather around the historical positions [15]. So the PSO is easy to fall into local extreme, premature convergence, or even calculation stop. 
Genetic algorithm (GA) is a highly parallel, random and adaptive search method based on the law of biological evolution (survival of the fittest). It directly takes the objective function as the search information, and then finds the optimal values through a probabilistic way [16]. So the GA can be implanted into the PSO to enhance the global search ability, speed up the evolution process, improve the convergence accuracy and avoid the premature convergence.

Based on the shortcoming of PSO and the superiority of GA, we propose a new algorithm GA-PSO to solve the load leveling optimization model of electric arc furnace. The GA-PSO is comprised of genetic algorithm and particle swarm optimization algorithm, where the crossover operator and mutation operator in GA are implanted into the PSO organically. Fig. 3 shows the flow chart of GA-PSO hybrid algorithm.

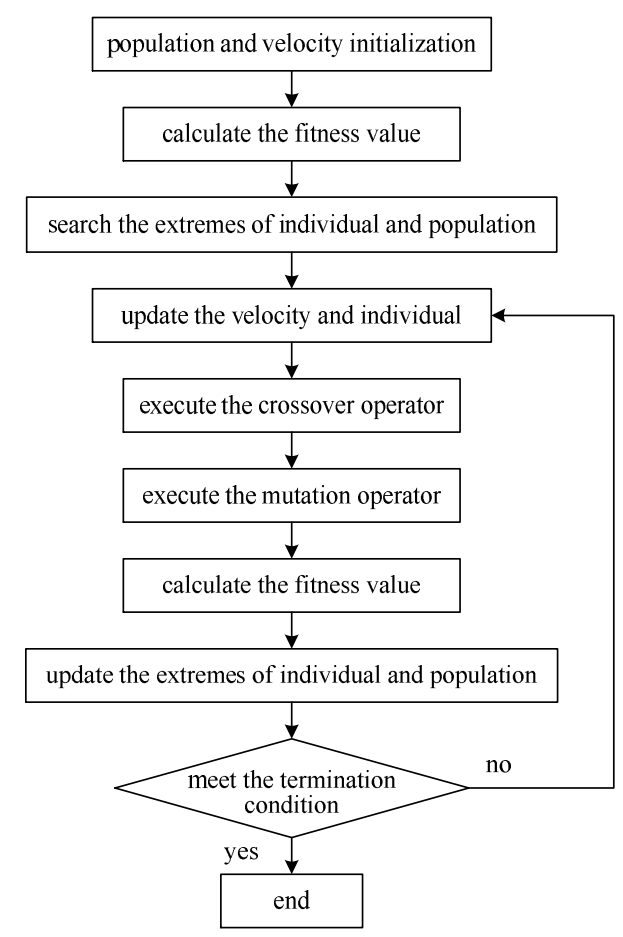

Fig. 3 Flow chart of GA-PSO hybrid algorithm.

\section{Optimization Results and Analysis}

In this part, we choose five same electric arc furnaces and five different electric arc furnaces as the calculation examples, and analyze their load fluctuation respectively in the two cases of synchronous operation and time-sharing operation. The optimal values of time-sharing operation about each electric arc furnace are solved, then the load leveling curves are drawn and their performance indexes are given, which will be used to verify the correctness and effectiveness of the load leveling strategy. It should be noted that the software we used is Matlab.

Five Same Electric Arc Furnaces Time-sharing Operation. The active power loads of five same electric arc furnaces are given:

$$
P_{i=1,2, \cdots, 5}(t)=\left\{\begin{array}{cr}
0, & 60 k<t \leq 3+60 k \\
40, & 3+60 k<t \leq 5+60 k \\
60, & 5+60 k<t \leq 25+60 k \\
50, & 25+60 k<t \leq 30+60 k \\
0, & 30+60 k<t \leq 33+60 k \\
40, & 33+60 k<t \leq 35+60 k \\
60, & 35+60 k<t \leq 55+60 k \\
50, & 55+60 k<t \leq 60+60 k
\end{array}\right.
$$


where, the unit of $P$ is $M W$, the unit of $t$ is $\min$.

Hence, the optimal values of time-sharing operation are solved:

$$
T_{\text {best }}=\left[t_{1}, t_{2}, t_{3}, t_{4}, t_{5}\right]=[0,12,24,36,48]
$$

The load leveling curves of active power are drawn in Fig. 4.

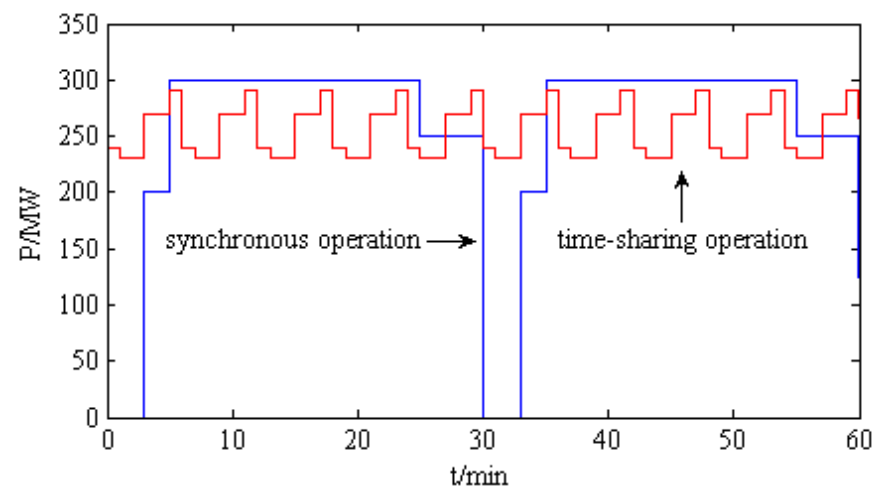

Fig. 4 The optimization results of five same electric arc furnaces.

The performance indexes of load leveling curve are given in Table 1.

Table1. The performance indexes of five same electric arc furnaces.

\begin{tabular}{ccc}
\hline operation condition & load curve variance $/ \mathrm{MW}^{2}$ & peak-valley difference $/ \mathrm{MW}$ \\
\hline synchronous operation & $8.06 \times 10^{3}$ & 300.00 \\
time-sharing operation & $5.25 \times 10^{2}$ & 60.00 \\
relative difference $/ \%$ & 93.57 & 80.00 \\
\hline
\end{tabular}

From Fig. 4 and Table 1, it can be seen obviously that the load fluctuation of five same electric arc furnaces is serious under the condition of synchronous operation, but it decreases greatly under the condition of time-sharing operation. More specifically, the load curve variance has been reduced by $93.57 \%$, and the peak-valley difference has been reduced by $80.00 \%$. The results show that the load leveling effect is significant with time-sharing operation strategy.

Five Different Electric Arc Furnaces Time-sharing Operation. The active power loads of the five different electric arc furnaces are given:

$$
P_{1}(t)=\left\{\begin{array}{cr}
0, & 60 k<t \leq 3+60 k \\
40, & 3+60 k<t \leq 5+60 k \\
60, & 5+60 k<t \leq 25+60 k \\
50, & 25+60 k<t \leq 30+60 k \\
0, & 30+60 k<t \leq 33+60 k \\
40, & 33+60 k<t \leq 35+60 k \\
60, & 35+60 k<t \leq 55+60 k \\
50, & 55+60 k<t \leq 60+60 k
\end{array}\right.
$$

where, the unit of $P_{1}(t)$ is $M W$, the unit of $t$ is $\min$. And $P_{1}(t)$ is as the basic load, it is the same with the load optimized in part $A$. 


$$
P_{2}(t)=\left\{\begin{array}{cr}
0, & 60 k<t \leq 3+60 k \\
30, & 3+60 k<t \leq 5+60 k \\
50, & 5+60 k<t \leq 25+60 k \\
40, & 25+60 k<t \leq 30+60 k \\
0, & 30+60 k<t \leq 33+60 k \\
30, & 33+60 k<t \leq 35+60 k \\
50, & 35+60 k<t \leq 55+60 k \\
40, & 55+60 k<t \leq 60+60 k
\end{array}\right.
$$

where, the unit of $P_{2}(t)$ is $M W$, the unit of $t$ is $\min$. And compared with the basic load $P_{1}(t)$, the active power amplitude of $P_{2}(t)$ is different.

$$
P_{3}(t)=\left\{\begin{array}{cr}
0, & 60 k<t \leq 3+60 k \\
40, & 3+60 k<t \leq 5+60 k \\
60, & 5+60 k<t \leq 25+60 k \\
50, & 25+60 k<t \leq 30+60 k \\
0, & 30+60 k<t \leq 33+60 k \\
50, & 33+60 k<t \leq 35+60 k \\
70, & 35+60 k<t \leq 55+60 k \\
60, & 55+60 k<t \leq 60+60 k
\end{array}\right.
$$

where, the unit of $P_{3}(t)$ is $M W$, the unit of $t$ is min. And compared with the basic load $P_{1}(t)$, the load shape coefficient of $P_{3}(t)$ is different.

$$
P_{4}(t)=\left\{\begin{array}{cr}
0, & 60 k<t \leq \quad 5+60 k \\
40, & 5+60 k<t \leq 10+60 k \\
60, & 10+60 k<t \leq 25+60 k \\
50, & 25+60 k<t \leq 30+60 k \\
0, & 30+60 k<t \leq 35+60 k \\
40, & 35+60 k<t \leq 40+60 k \\
60, & 40+60 k<t \leq 55+60 k \\
50, & 55+60 k<t \leq 60+60 k
\end{array}\right.
$$

where, the unit of $P_{4}(t)$ is $M W$, the unit of $t$ is min. And compared with the basic load $P_{1}(t)$, the period of each stage of $P_{4}(t)$ is different.

$$
P_{5}(t)=\left\{\begin{array}{cr}
0, & 70 k<t \leq 5+60 k \\
40, & 5+70 k<t \leq 10+70 k \\
60, & 10+70 k<t \leq 30+70 k \\
50, & 30+70 k<t \leq 35+70 k \\
0, & 35+70 k<t \leq 40+70 k \\
40, & 40+70 k<t \leq 45+70 k \\
60, & 45+70 k<t \leq 65+70 k \\
50, & 65+70 k<t \leq 70+70 k
\end{array}\right.
$$

where, the unit of $P_{5}(t)$ is $M W$, the unit of $t$ is min. And compared with the basic load $P_{1}(t)$, the total operation cycle of $P_{5}(t)$ is different.

Hence, the optimal values of time-sharing operation are solved:

$$
T_{\text {best }}=\left[t_{1}, t_{2}, t_{3}, t_{4}, t_{5}\right]=[0,20,25,35,45]
$$

The load leveling curves of active power are drawn in Fig. 5. 


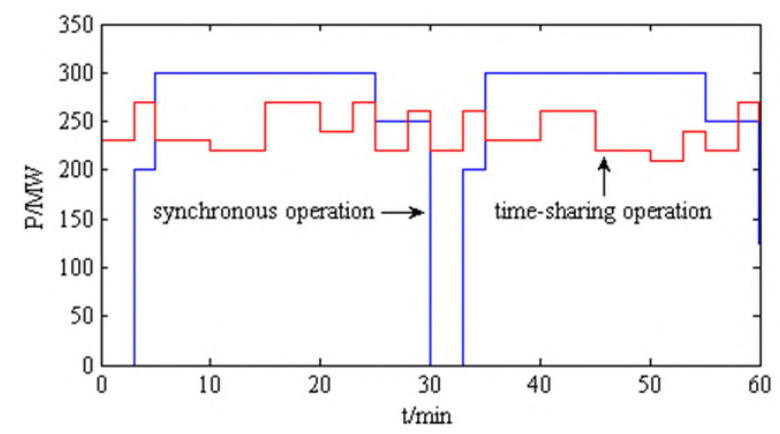

Fig. 5 The optimization results of five different electric arc furnaces.

The performance indexes of load leveling curve are given in Table 2.

Table 2 The performance indexes of five different electric arc furnaces.

\begin{tabular}{ccc}
\hline operation condition & load curve variance $/ \mathrm{MW}^{2}$ & peak-valley difference $/ \mathrm{MW}$ \\
\hline synchronous operation & $8.07 \times 10^{3}$ & 300.00 \\
time-sharing operation & $4.16 \times 10^{2}$ & 70.00 \\
relative difference $/ \%$ & 94.85 & 76.67 \\
\hline
\end{tabular}

From Fig. 5 and Table 2, it can be seen obviously that the load fluctuation of five different electric arc furnaces is serious under the condition of synchronous operation, but it decreases greatly under the condition of time-sharing operation. More specifically, the load curve variance has been reduced by $94.85 \%$, and the peak-valley difference has been reduced by $76.67 \%$. The results prove that the time-sharing operation strategy is effective in load leveling.

Analysis and Discussion of Optimization Results. According the optimization results in part $A$ and part $B$, we can see that the load fluctuation of time-sharing operation is far less than that of synchronous operation, which indicates that the proposed optimization strategy has an obvious effect to stabilize the synthetic load of electric arc furnaces. Moreover, if we increase the number of electric arc furnaces, or add some other types of production loads, even extend to the joint optimization of different enterprises, the load leveling strategy will be more effective and the synthetic load curve will be flatter.

Taking the time-sharing operation strategy to electric arc furnaces, the main purposes are to adjust the load curve and optimize the load characteristic. However, the direct effects are reducing peak load and increasing the valley load, then make the load curve be more close to a horizontal line. When it shows in the performance indexes, the load curve variance will be reduced, and the peak-valley difference will be cut down, therefore the load factor will be promoted.

The practical implication is that it will improve the asset utilization of electrical equipment in power system, minimize the coal consumption of generator set, reduce the capacity margin of electric equipment, and cut down the loss of line in power grid. On the other hand, it will reduce the effect of impact load to the industrial enterprises, ensure the safe and stable production, improve the quality of product, and realize the energy saving and consumption reducing.

\section{Conclusion}

In this paper, a new load leveling strategy called time-sharing operation is proposed, which is used to stabilize the load of electric arc furnace in iron and steel enterprises. Firstly, the working principle and load characteristic of electric arc furnace are introduced, and then the active power load curve of single electric arc furnace is given. Based on these, the load leveling optimization model of multiple electric arc furnaces is built, and a new GA-PSO hybrid algorithm is adopted to solve the model. The two calculation examples of five same electric arc furnaces and five different electric arc furnaces are optimized respectively. The optimization results show that the load fluctuation of time-sharing operation is far less than that of synchronous operation, which indicates that the time-sharing operation strategy is effective in load leveling. The research has important significance to reduce the 
loss of line in power grid, ensure the production of enterprise safely and stably, and improve the quality of product in iron and steel enterprises.

\section{References}

[1] M. Yuan, Z. Y. Yao and L. L. Liu, et al. Model of electric arc furnace load for harmonic analysis of power supply system, The 7th Academic Conference on Power Quality. Chengdu: Committee on Standard Voltages, Current Ratings and Frequencies, 2014: 143-148.

[2] L. Dong, Z. G. Hao and G. Jing. A novel electromagnetic transient modeling of impact load of arc furnace, Smart Grid, 3(8) (2015) 690-695.

[3] H. X. Lin, Influence of active power impact caused by EAF on the generating sets, Proc. CSEE, 34(s) (2014) 232-238.

[4] Y. T. Huang. Research on load profile analysis and load management optimization, Hangzhou: College of Electrical Engineering, Zhejiang University, 2013.

[5] X. Xiao, Y. H. Zhou, K. Z. Zheng, et al. Research on strategy of interruptible price and its cost-benefit model aimed at peak load shifting in Taiwan, Proc. CSEE, 34(22) (2014) 3615-3622.

[6] T. Y. Li, X. W. Zhao and W. J. Xiao, Regulation technology of air-conditioning load in commercial buildings for balance of power grid peak and valley, Automat. Electric Power Syst. 39(17) (2015) 96-101.

[7] C. Xiong and R. Ma. A Pareto optimal model for energy storage battery in distribution network considering network loss and peak-valley difference alleviation, Electric Power Constr. 36(8) (2015) 34-40.

[8] H. Y. Han, J. H. He and X. J. Wang, et al. An improved particle swarm optimization-based load response strategy with participation of vehicle to grid, Power Syst. Technol. 35(10) (2011) 165-169.

[9] S. Y. Ge, J. Y. Guo and H. Liu, et al. Impacts of electric vehicle's ordered charging on power grid load considering demand side response and output of wind farm and photovoltaic generation. Power Syst. Technol. 38(7) (2014) 1806-1811.

[10] Y. Fu, Y. L. Jiang and Z. K. Li, et al. Optimal economic dispatch for micro grid considering shiftable loads, Proceedings of the CSEE, 34(16) (2014) 2612-2620.

[11]L. Feng, Research on improved multi-objective particle swarm optimization algorithm and its application in power curve of electric arc furnace, Shenyang: Northeastern University, 2012.

[12] L. Y. Li, Modeling and optimization of power supply system for AC electric arc furnace, Tianjin: Tianjin University of Technology, 2011.

[13] J. Xie. The research on a new type electric arc furnace power system with dynamic compensation function, Changsha: Hunan University, 2014.

[14] S. Q. Ding, S. Man and C. Cui, et al. Simulation of STATCOM for electric arc furnace governance, Proc. CSU-EPSA, 25(1) (2013) 155-160.

[15] S. W. Yu. Case analysis and application of MATLAB optimization algorithm, Beijing: Tsinghua University Press, 2014.

[16]Q. Y. Chen, W. R. Chen and C. H. Dai, et al. Reactive power optimization based on modified particle swarm optimization algorithm for power system, Proc. CSU-EPSA, 26(2) (2014) 9-13. 